\title{
Why are we waiting?
}

Although Mr Mulley, UK Secretary for Education and Science, has had the report of the Williams Working Party on Genetic Manipulation of Microorganisms on his desk for well over a month, it is due to remain there for at least a "few more weeks". Until then scientists will be in the dark over the details of the code of practice that will apply to recombinant DNA research in Britain. There are several possible excuses for Mr Mulley's tardiness. None of them is good enough.

The Williams Working Party had its origins in a statement published by Professor Paul Berg and his colleagues in July 1974 in which they expressed concern at some of the possible consequences of the research they themselves had pioneered. The improbable pathway to disaster that they foresaw involved the escape from laboratory containment of bacteria whose genes had been experimentally recombined with genetic material from another organism, the survival of those bacteria in the outside world, their colonisation of the human intestine and the expression of their foreign genetic component to the detriment of the human host.

That scenario was taken seriously enough on both sides of the Atlantic that most scientists have since held to a voluntary moratorium on suspect research. American concern, latterly under the auspices of the National Institutes of Health, culminated four weeks ago in the issue of a complex series of guidelines. The British wheels were set in motion in July 1974 with the Ashby Working Party, convened by the Advisory Board for the Research Councils, which reported in December of that year. Seven months later $\mathrm{Mr}$ Mulley set up the Williams Working
Party to produce a code of practice and to consider the establishment of a central advisory service for laboratories carrying out the procedures in question.

The Williams Working Party report is unlikely to contain many surprises. It will not recommend the proscription of any particular experiments but will suggest the precautionary measures that are appropriate for various categories of research. Few specific experiments will be quoted and no attempt to quantify their dangers will be made. The report is expected to endorse Ashby's suggestion of a central advisory service and to recommend how it might operate.

The scientific community anxiously awaits the report and $\mathrm{Mr}$ Mulley's reactions to it. The longer they have to wait for a go-ahead on experiments which in some cases have been on ice for two years, the worse (whatever the precautions suggested) will become the atmosphere of frustration and suspicion that has gradually built up. Inevitably moratorium-breaking has already occurred, and the consequences for those involved have on occasion been unpleasant.

Why then is $\mathrm{Mr}$ Mulley keeping us waiting? One possibility is that he is reserving the right to modify his reactions in the light of the response at home and abroad to the American guidelines. If so the delay could well be lengthy in view of the recent clash between Cambridge (Massachusetts) City Council and Harvard University. The trouble arose when the Mayor of Cambridge attempted to block plans to build a high containment laboratory within the Harvard Biological Laboratories; at the moment there is a threemonth moratorium during which the council will review the position before deciding on the future of Harvard's genetic engineers. Similar problems are expected in other American cities. Although there is a reasonable chance that such clashes will be avoided in Britain, the longer Mr Mulley delays, the more likely they are to occur.

A second reason for delay may simply be the need for extensive briefing and consultation between departments. If so $\mathrm{Mr}$ Mulley must lavishly oil the cogs of bureaucracy. Most likely the delay is due to his consideration of the introduction of statutory controls of recombinant DNA research. Although the Working Party is thought to have been reluctant to recommend statutory controls, they may have made some suggestions in that direction because of forceful representation from the unions. The same pressures, which clearly must be respected since the unions represent those most likely to be directly carrying out the research, may now be holding $\mathrm{Mr}$ Mulley back.

The British code of practice, with or without statutory backing, could be very influential. In contrast to the American code, which applies only to NIH-supported research, the British code will apply to all academic institutes and probably also to industry via the Health and Safety Executive. If that breadth is matched by an authoritative depth and practical recommendations, the code could well be adopted by other European countries. That could happen through the European Molecular Biology Organisation which meets to consider the matter on August 12. It would be a great pity if the British code had not emerged by then.

\section{Solar energy breeders}

\section{Malcolm Slesser and Ian Hounam of the Energy Studies Unit at the University of Strathclyde, Glasgow, offer an opinion on a largely ignored aspect of solar energy}

SOLAR energy has not been taken seriously as a solution to our energy supply problem and for good reason. It requires considerable land area and the sun has an unhappy knack of ducking behind clouds or withdrawing into a winter solstice. But there is one aspect of solar energy that is significantly in favour of its large scalc development, an aspect which has so far received scant attention. This is the potential for solar energy devices to breed energy. No other device can do that. Yet, given the right technology, we calculate that with an initial invest- ment by 1980 in $1 \mathrm{MW}$ of solar power, it would be possible for solar energy to provide $90 \%$ of the world's energy needs within 40 years, without placing any burden upon existing energy resources.

The importance of this claim can hardly be exaggerated. If a solar breeder system was in operation, nearly all the energy from North Sca oil could be devoted to current needs and not, for example, to building alternative energy systems that will be needed when oil runs out. If we have a viable solar breeder system, world- wide, then once that system has grown large enough to satisfy the bulk of world demand the price of energy will fall to a trivial value, because after all the sun is a free good. Such a fact would utterly change the basis of a manufacturing or even a service orientated economy.

What, then, is an energy breeder? It is a device which "breeds" capacity to generate useful energy without consuming energy stocks. In this sense nuclear "breeders" are not breeders but extenders, increasing the potential energy of uranium by roughly $100 / 0.7$, where the 0.7 is the proportion of Uranium 235 occurring in natural uranium. But when a solar capture device (SCD) (or any solar induced device such as a wind or wave gener- 
ator) delivers in its lifetime more energy than needed to maintain and rebuild itself, then some of that surplus can build more SCDs, thus breeding energy.

Breeding success depends on the payback time of the initial energy of manufacture, and energy analysis provides us with a means of assessing it. Through a method known as dynamic net energy analysis, in which energy required to construct and service an energy production or transformation system is set against the system output as a function of time, one can test various breeding scenarios. Unfortunately the energy investment data so far produced on constructing solar energy devices (other than solar heat devices) is unconvincing, and tends to consider only optimal sunlight conditions. Moreover, all too often figures include only direct energy costs, and the more obvious ones like the energy requirements of structural steel and glass. No comprehensive results have been published enabling one to estimate the gross energy requirement to build and operate an SCD in an average situation.

Our own tentative energy analysis of 1972 photo-voltaic technology has shown it would take about 40 years output to pay for the energy investment, and since its expected life may be about 30 years it is clearly a sink, not a breeder. However, the new technology of ribbon melting of silicon looked like reducing that to 10 years. In recent discussions with the Office of Technology Assessment in the USA we have learnt of systems which are said to require only a two-year pay-back time. This clearly provides tremendous breeding potential.

If a system could grow while also satisfying its own energy needs-that is to say the energy for construction and operation-it then places no burden on the existing fossil and nuclear energy infrastructure, and the only charge upon the building programme is the labour and management and the land needed for expansion of the system.

Choosing a datum of 1980 for the initiation of the programme of breeding, with an initial $1 \mathrm{MW}$ output capacity SCD system, we examined a range of pay-back times varying from the pessimistic result at Strathclyde (10 years) to the optimistic views of the Office of Technology Assessment (2 years) for various investment policies, to show that energy breeding is a possibility even with as large a value of pay-back time as 10 years, though the rate of breeding is too low to be of real interest. Thus for a policy of $5 \%$ investment in new capacity, by 2030 the programme would only have developed an output capacity of
12.2 MW (as against the original $1 \mathrm{MW}$ in 1980) and a net output power would bc a mere $4.3 \mathrm{MW}$-reflecting a system doubling time of about 14.5 years. Yet even that is greater than the global rate of growth in energy demand.

On the other hand, if we accept the optimistic value of pay-back time of 2 years being claimed in some quarters, an SCD breeding programme could be spectacularly successful. For example, with an investment fraction of $40 \%$, an initial output capacity of $1 \mathrm{MW}$ in 1980 would have grown to an output capacity of $8.8 \times 10^{6} \mathrm{MW}$ by 2020 , giving a net power output to the nonsolar energy sector of the economy of $1.7 \times 10^{6} \mathrm{MW}$. By this time the doubling time of the SCD system is only 3.2 years, a rate of growth of energy supply higher than the most horrific energy demand scenarios.

Of course by no means all problems are solved. Though the programme provides its own energy requirements, there are still the problems of land availability and manpower. Some will point out that there is also a need for steel, glass and so on. But of course, the energy analysis has taken that into account through the energy required for construction. Nevertheless, there remains the task of assessing whether the necessary industrial infrastructure to sustain the solar programme can be created, a question we do not attempt to answer here. We merely set out to show that, given the appropriate technology (low pay-back time), a solar capture system could breed itself, and hence in time solve the global energy supply problem. The devices with larger than two-year pay-back times are less satisfactory. Clearly, then, in view of the tremendous opportunities presented by a device with a two-year pay-back time, a massive research programme is justified.

The SCD system output capacity could match even the most ambitious forecasts of demand $\left(4.5 \times 10^{6} \mathrm{MW}\right)$ within 40 years of initiation. From an initial recycle fraction of $80 \%$ to new investment, the construction programme falls away to $7 \%$ in the 40 th year. In net energy terms this is a lower figure than found in our present fossil and nuclear fuel industries. It would be consistent with a price, in current terms, of around $£ 100$ per $\mathrm{kW}$ for photo-voltaic collectors.

It is interesting to consider what happens to the cost of conventional fossil and nuclear fuels if such a programme took place. By the year 40 (2020), solar energy could so nearly supply all energy needs that oil, gas, coal and nuclear sources will have lost much of the scarcity value they now enjoy. True, oil and gas will remain valuable for their feedstock potential, but nuclear reactors could be rendered redundant and coal mining unnecessary, save as a source of carbon. In such a situation presumably the price of energy falls to a trivial value.

This is offset by the land requirement of SCDs. Taking the 40 year level of output of $4.2 \times 10^{6} \mathrm{MW}$, and assuming that the two-year pay-back time has been achieved, with collection of $20 \%$ efficiency, a huge land area is required, around $30,000 \mathrm{~km}^{2}$ (equivalent to about $12 \%$ of the British Isles), but it is spread world wide. However, if the same period of two-year payback time applies to solar generated SCDs such as wave and wind power generation, then land requirement falls considerably.

In order to effect the programme, a cumulative energy investment of $1.7 \times 10^{6} \mathrm{MW}$ years of energy would have been used-that is about $25 \times 10^{9}$ tons coal equivalent. This is a huge quantity of energy, and reflects a huge amount of material and man power. None of that energy, however, would have come from global energy resources, but from within the programme. Secondly, the basic problem facing all industrialised societies is the need to build a new energy infrastructure within the next $30-50$ years. When we examined the task of doing this for the UK imagining an eventual replacement of fossil energy by nuclear and some solar, we found that the massive energy investment called for placed restrictions of UK export of North Sea oil, and a serious limitation on UK economic growth, for the energy investment had to come from existing energy resources and transformation devices. The SCD breeding system, however, permits a parallel economic development without this strain being placed on existing energy resources.

In reality an SCD breeding programme would differ considerably from the simple model presented here. For one thing much of this growth would be disversed-some citizens for example, building wind generators in their back yards. Technology would change rapidly, and pay-back times would vary according to the sophistication and purpose and location of the device. Much solar energy could be turned directly to heat, through collectors. It is still too early to find whether the torrid dunes of the Sahara will pay a more or less important role than the ceaseless waves of the North Atlantic and South Pacific. But given a short pay-back time and an integrated breeding and development programme, prospects for a low cost energy, nuclear-free world do look good. 